\title{
Snack (Re)formulation in the Improvement of Health Effects on Glycaemia and Satiety Responses: Preliminary Results
}

\author{
Mary R. Yan 1,2,", Elaine C. Rush2, Ruth Jackson', Shamim B. Shaikh1 \\ ${ }^{1}$ Health and Community Sciences, Unitec Institute of Technology, Auckland, New Zealand \\ ${ }^{2}$ AUT Food Network, Auckland University of Technology, Auckland, New Zealand \\ Email: *myan@unitec.ac.nz
}

How to cite this paper: Yan, M.R., Rush, E.C., Jackson, R. and Shaikh, S.B. (2020) Snack (Re)formulation in the Improvement of Health Effects on Glycaemia and Satiety Responses: Preliminary Results. Food and Nutrition Sciences, 11, 649-658. https://doi.org/10.4236/fns.2020.117046

Received: June 5, 2020

Accepted: July 6, 2020

Published: July 9, 2020

Copyright $\odot 2020$ by author(s) and Scientific Research Publishing Inc. This work is licensed under the Creative Commons Attribution International License (CC BY 4.0).

http://creativecommons.org/licenses/by/4.0/

\begin{abstract}
Snacking impacts the overall quality of dietary patterns, nutrition and health outcomes. Highly processed snack foods are normally unhealthy due to higher saturated fat content, refined grains (carbohydrates), and artificial ingredients. Snack product (re)formulation using plant-based wholesome ingredients has the potential to improve health effects including glycaemia, satiety responses, and lipid metabolism. Oat (Avena sativa L.) has gained increased popularity as a food item in recent decades due to its perceived or real health benefits, principally related to the bran content of oats. We have developed a healthier snack prototype using rolled oats as main ingredients. Other ingredients include oat bran, dried fruits, and nuts. For initial trials, these ingredients were combined in various combinations and composition to produce a formula having a good nutrient profile score $(\leq 4)$ that meets the criteria of FSANZ for making health-related claims. The proportions of the ingredients in the formula were adjusted to enable higher fiber and protein contents. From the initial 10 combinations prepared, one prototype was selected based on four quality attributes (visual appearance, texture, taste, and water activity). The selected prototype was tested for glycemic index $(\mathrm{n}=10)$ and consumer liking $(n=67)$. Our preliminary results demonstrated that the prototype has a low glycemic index, favorable satiety effects compared with glucose, and has acceptable taste compared with two commercial products. This formulation will be refined further when we plan to assess its effects on glycaemia and insulin profiles. High value nutrition is the New Zealand national science challenge. An approach of developing healthier snack products with verifiable health-related claims through (re)formulation could be translated into relevant dietary changes associated with potential improvement in public health.
\end{abstract}




\section{Keywords}

Snack (Re)formulation, Industrial Food Solutions, Food Labelling, Nutrition, Public Health

\section{Introduction}

Snacking impacts the overall quality of dietary patterns, nutrition and health outcomes, in particular, body weight and obesity [1] [2] [3]. Snacking, the consumption of food and drinks between the three main meals, is greatly predominant worldwide [1] [4]. It has been reported that $53 \%$ of women snack several times a day and over $85 \%$ of women snack at least once a day [5]. In fact, the choices and dietary quality of snack food are associated with the quality of life and health [1] [2]. Highly processed snack foods are normally unhealthy due to higher saturated fat content, refined grains (carbohydrates), and artificial ingredients. In general, snack foods are energy-dense, nutrient-poor, and rich in sugar, fat and sodium. In New Zealand, most frequently consumed snack products are muesli bars, biscuits, cakes and pies [6].

With increasing health awareness, consumer demand for healthier snacks is shaping the market trends which in turn has stimulated industrial and health professionals' endeavor in food (re)formulation. Reducing sugar, fat, and sodium in packaged food products are important consumer-driven trends [7] [8] [9]. In addition, consumers focus more on specific nutrients such as whole grains, proteins, and dietary fiber [10]. "Power to the plants" has become a global food and drink trend [11]. Intake of whole grains, fruit, nuts/seeds, and vegetables has been demonstrated to be positively associated with health [12] [13]. Whole grains foods have lower glycemic impact than their refined equivalent. The accumulated evidence supports public health recommendations to replace refined grains with whole grains to reduce the risk of developing type 2 diabetes mellitus [14]. In addition, high fiber content in whole grains is demonstrated to be associated with increased satiety (feeling of fullness) and subsequently a reduction in food intake [15]. The regulation of hunger and satiety is believed to have beneficial impact on health, for example, reducing the risk of obesity [16]. Snack product (re)formulation using plant-based wholesome ingredients (e.g. rolled oats) has potential in the improvement of health effects on glycaemia and satiety responses.

Furthermore, clear and valid front-of-pack food labelling promotes healthier purchasing intention. However, in New Zealand, most of snack products that carried health-related claims are actually "less healthy" according to the Food Standards Australia New Zealand (FSANZ) health claims legislation [17]. This warrants additional efforts from researchers and industry partners towards reformulating snack products with validated health claims.

The present study aimed to develop a healthier snack prototype using whole- 
some plant-based ingredients that has a low glycemic index, favorable satiety effects, and is accepted by consumers.

\section{Materials and Methods}

\subsection{Product Development}

The initial trials were conducted in a commercial kitchen at Unitec Institute of Technology, New Zealand. The potential ingredients were selected based on their nutritional and health related properties, and FSANZ nutrient profiling model [18] was used as a tool to develop a healthier prototype. Oat (Avena sativa $L$.) has gained increased popularity as a food item in recent decades due to its perceived or real health benefits, such as modulation of glucose metabolism, regulation of satiety, and reduction of low density lipoprotein, principally related to the bran content of oats [19] [20] [21]. In the formula developed in this study, rolled oats were used as the main ingredient. Other ingredients included oat bran, dried fruits and nuts, and sunflower oil. Dried kiwifruits were added to enhance the taste and flavor. Kiwifruit has a clinically proven role in managing blood glucose [22].

Raw ingredients were sourced from supermarkets in Auckland, New Zealand. Dried kiwifruits were provided by the Little Beauties Ltd., New Zealand. The ingredients were trialed in different combination and composition to produce a formula having a good nutrient profile score and acceptable taste.

The nutrition profile of the formula was analyzed using FoodWorks ${ }^{\mathrm{Tu}}$ software (Xyris Pty Ltd., Australia) and the New Zealand food composition database. A food with a nutrient profile score (NPS) $\leq 4$ allows the product to support general and high level health claims [18].

Ten formulas with varying combinations were trialed therefore 10 prototypes were produced in the early product developmental stage. The proportion of rolled oats and oat bran (ratio $80: 20$ ) was $46 \%$ as the main ingredients, and that of dried fruits and almonds were approximately $21 \%$ and $14 \%$, respectively. The proportions of the ingredients in the formula were adjusted to enable higher fiber and protein contents. The 10 prototypes were informally evaluated for four quality attributes: visual appearance, texture, taste, and water activity by two researchers and four consumers who consume snack regularly. A lower water activity $\left(\alpha_{w}<0.7\right)$ ensures a stable shelf life. Based on the perceptions of quality attributes, one formula was selected to test the glycemic index, satiety responses, and consumer liking.

\subsection{Participants}

This study protocol was approved by internal institutional ethics committee (Unitec Research Ethics Committee, approval \#2018-1031) for carrying out preliminary trials in human participants. All participants signed consent form prior to the start of the trials.

First part of the trials comprised of glycemic index (GI) and satiety responses 
of consumption of the developed prototype. Ten healthy participants were recruited in the study [23]. Exclusion criteria were having impaired glucose tolerance, any illness, food allergy to any of the ingredients in the prototype.

The second part of the trials was consumer liking assessments. Sixty-seven untrained participants were recruited in the study. People were eligible if they were 18 years or older, had no known allergies to any of the ingredients in three snack products (Table 1 ).

\subsection{Glycemic Index (GI) and Satiety Responses}

\subsubsection{Sample Preparation}

The samples of the developed prototype were prepared and kept in a fridge at $4^{\circ} \mathrm{C}$. On the testing day, the samples were prepared in a portion size containing $25 \mathrm{~g}$ of available carbohydrates. A standard $25 \mathrm{~g}$ glucose drink (Thermo Fisher Scientific, Australia) was used as the reference food.

\subsubsection{GI and Satiety Measurements}

Glycemic index was measured in vivo in 10 healthy participants, using the international standard method ISO 26642:2010(E) [23]. The test was conducted in the morning after 10 - 12 hours of overnight fast. Capillary blood samples were collected from finger pricking using sterile disposable lancets. The blood glucose concentration was then measured by using HemoCue Glucose 201+ analyzer (HemoCue ${ }^{\circledast} \mathrm{AB}$, Angelholm, Sweden). Before a finger prick, participants were encouraged to warm their hand to increase the blood flow. The fasting blood glucose concentrations were measured at 0 and 5 minutes. The mean of these two readings was used as the baseline. Following the baseline tests, a weighted portion of the snack sample containing $25 \mathrm{~g}$ of available carbohydrate was consumed within 10 minutes. Participants' capillary blood samples were analyzed for glucose at 15, 30, 45, 60, 90, and 120 minutes after the start of the ingestion of a test food. On another day, a drink containing $25 \mathrm{~g}$ of glucose was consumed by the same 10 participants and same procedure was repeated. A $250 \mathrm{ml}$ of water was provided to each participant on both occasions.

The incremental area under the blood glucose curve (iAUC) was calculated using the trapezoid model and the area below the baseline excluded [23]. The mean iAUC of the reference food and the mean iAUC of the prototype were used to calculate the GI of the prototype. The GI of the prototype was calculated using the formula below.

$$
\mathrm{GI}=\frac{\Delta \mathrm{AUC} \text { for } 25 \mathrm{~g} \text { carbohydrate from snack food }}{\Delta \mathrm{AUC} \text { for } 25 \mathrm{~g} \text { glucose }} \times 100
$$

Satiety is a subjective concept therefore it is only measured indirectly. Generally, satiety is measured by rating subjective feeling of fullness before and after eating the test food or meal [24] [25]. In this study, participants were asked to rate their feeling of hunger, satiety, fullness, the amount that could be eaten at 0 , $30,60,90,120$ minutes after blood sampling, on a $100 \mathrm{~mm}$ visual analogue scale which is verbally anchored e.g. "not at all" and "extremely" at the endpoints. 
Table 1. Sensory attribute ratings from consumer study $(n=66)$, comparing of the new prototype with two commercial products.

\begin{tabular}{ccccc}
\hline \multirow{2}{*}{$\begin{array}{c}\text { Product }^{1} \\
\text { Attributes }(\mathrm{mm})\end{array}$} & ONF & MOE & NV & \multirow{2}{*}{${ }^{*} p$ value } \\
\cline { 2 - 4 } Color & $63(1.83)^{\mathrm{a}}$ & $65(2.51)^{\mathrm{a}}$ & $66(1.83)^{\mathrm{a}}$ & 0.440 \\
Texture & $52(2.14)^{\mathrm{a}}$ & $68(2.10)^{\mathrm{b}}$ & $66(2.82)^{\mathrm{b}}$ & 0.001 \\
Taste & $55(2.37)^{\mathrm{a}}$ & $68(2.48)^{\mathrm{b}}$ & $71(2.48)^{\mathrm{b}}$ & 0.001 \\
Overall liking & $53(2.29)^{\mathrm{a}}$ & $70(2.29)^{\mathrm{b}}$ & $71(2.14)^{\mathrm{b}}$ & 0.001 \\
\hline
\end{tabular}

${ }^{1}$ The snack prototype and two commercial products were coded as ONF, MOE, NV, respectively. The mean values of the replicate tests; ${ }^{*}$ ANOVA, SE (standard error); Within the same row, differences were identified with superscript letters a and $\mathrm{b}$ at $p<0.05$. ONF ingredients: rolled oats, oat bran, almonds, cinnamon, dates, kiwifruits, sunflower oil, glycerin; MOE ingredients: wholegrain oats, butter, golden syrup, dates, egg powder, brown sugar, vegetable oil, glycerol; NV ingredients: rolled oats, sugar, honey, sunflower oil, salt, molasses, raising agent.

Percent distance data along the visual analogue scale of satiety responses to the snack prototype were plotted and compared with that of glucose drink.

\subsection{Consumer Liking Assessment}

\subsubsection{Sample Preparation}

The samples of the prototype were prepared and kept in a fridge. The two commercial snack products, which have similar ingredients with oats as the main component, were purchased from the local supermarket in Auckland, New Zealand.

The prototype was coded as ONF. The two commercial products were coded as MOE and NV (Table 1), their nutrient profile scores were 14 and 11, respectively. Snack samples were cut into a $2 \times 2 \mathrm{~cm}^{2}$ pieces and were presented to the consumers at room temperature $\left(20^{\circ} \mathrm{C}\right)$ in white, covered food grade plastic containers. To reduce participant and researcher bias, the sample containers were labeled with individual three digit codes, which were randomized, and counter balanced to order of presentation using a Latin square design [26]. The brands of snack products were blind to participants.

\subsubsection{Consumer Liking Measurement}

The consumer liking assessments were carried out to evaluate the product acceptability. Sixty-seven untrained consumers were recruited to evaluate how well the prototype is likely to be accepted by the members of public, compared with the two commercial products. The liking attributes include color, texture, taste, and overall liking. The test food was presented to each participant on plastic plates. Water was provided to participants to rinse mouth before tasting the next sample. Participants were required to complete questionnaires to evaluate their liking in relation to color, texture, taste, and overall liking on four unstructured line scales anchored at extremely dislike (left end) and extremely like (right end) [27] (Figure 1). 


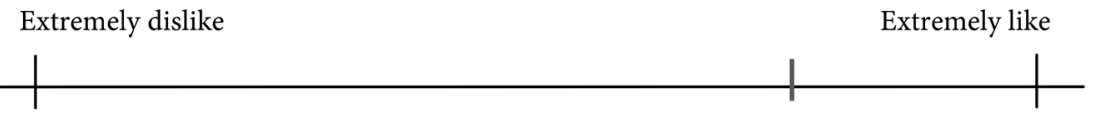

Figure 1. Line scaling for measuring consumer liking/disliking in relation to sensory attributes on a $100 \mathrm{~mm}$ visual analogue scale (VAS).

Percent distance data along the line was the raw data to ultimately establish the relationships between the product characteristics and participants' perceptions. The means of hedonic liking on four sensory attributes (color, texture, taste, and overall liking) were calculated and statistically tested using one-way analysis of variance (ANOVA) to determine if a statistical difference existed at $p$ $<0.05$. The effects of age, gender and ethnicity on liking were analyzed using two-way ANOVA. The statistical analysis was performed by using SPSS version 26.0 (IBM Corporation, US).

\section{Results}

The formulation and composition of the selected prototype was finalized after experimental trials and tasting. The nutrition profile score of the prototype was 1. The health star rating was 4.5 (a scale of 0.5 - 5, Figure 2).

The prototype has been tested for glycemic index $(n=10)$ and satiety effects. The results revealed that the prototype has a low glycemic index (GI $=51)$, favorable satiety effects compared with the standard glucose drink. Consumption of the snack prototype induced higher fullness and lower hunger sensations compared to that of glucose drink (Figure 2).

With regard to consumer liking assessment, of sixty-seven participants (45\% male, $55 \%$ female; $42 \%$ Asian, $58 \%$ non-Asian), one participant was excluded from the data analysis due to missing data. The consumer liking assessment $(\mathrm{n}=$ 66) revealed that the developed prototype was sensory acceptable. Of the four liking attributes (color, texture, taste, overall), there was no significant difference in color ratings between three snack samples (ONF, MOE, and NV). The ratings on texture, taste, and overall liking of the snack prototype (code ONF) were relatively lower compared to two commercial snack products (Table 1). However, the ratings of all four liking attributes to the snack prototype were above the center point of the scales, from the just-right-center-choice point of view [28]. The liking attributes of the tested samples did not show meaningful differences based on participants' age, gender and ethnicity.

\section{Discussion}

The preliminary results from the study revealed that the prototype has a low glycemic index $(\mathrm{n}=10)$, favorable satiety effects compared with glucose, and it is sensory acceptable $(n=66)$. The reported study was the first stage of the project. We are aiming to study the health effects of the prototype on glycaemia and insulin profiles in the next stage using a larger number of participants. 

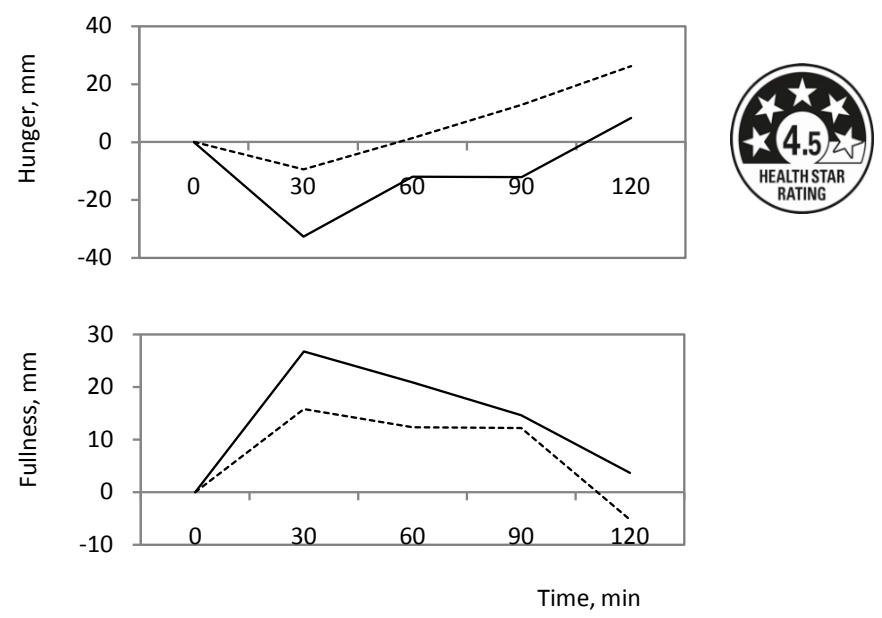

Figure 2. Mean changes $(\Delta, \mathrm{n}=10)$ in self-reported hunger, fullness for the developed prototype (solid) compared with glucose drink (dots).

In recent years, consumption of plant-based food has become a global trend associated with sustainability and human and planetary health. In 2016-17, there has been a steady increase in the use of food-related claims e.g. "natural product and ingredients" (29\%) and "ethical and environmental" (22\%) on global food and drink product launches [11].

Food reformulation for health involves rebalancing macronutrients. Reduction of unhealthier nutrients including sodium, saturated fat, and sugar and addition of healthier nutrients such as dietary fiber through reformulation is the tactic of the techniques to achieve the goal [29] [30]. Using unrefined ingredients to improve the nutrient profile of food products is an effective approach. In the present study, the health benefits of selected plant-based ingredients contributed to the overall nutrition profiles of the snack, as have already been demonstrated by studies on oats [13], oat bran [20], almonds [15], cinnamon [31] [32] and kiwifruits [22].

Food product development for prevention of chronic diseases, with formulations that are healthier, flavorful and easy to consume, is challenging but has potential approaches. Nevertheless, some thought provoking questions have already been raised by researchers, such as "will food reformulation in isolation provide an efficient solution to the challenge of improving dietary patterns" [33]? Further, will food reformulation result in beneficial health outcomes equitably? These questions need to be further studied. In addition, consumers do not trust food labels because of the misleading tricks for marketing purpose [34]. Consumers are expecting food labels to be more honest. The reports such as that published by Al-Ani et al. and Lytton TD [17] [34] draw the attention to the need of regulation on food labeling, as part of the regulatory requirements.

\section{Conclusion}

We have developed a snack prototype using plant-based wholesome ingredients and demonstrated that the prototype has a good nutrient profile score, a low 
glycemic index, favorable satiety effects compared with glucose, and is sensory acceptable. New Zealand has developed international reputation in food safety and quality related to the natural environment. Snack food development using local plant-based ingredients such as oats, flaxseed, fruits would add value for domestic consumers and export markets. High value nutrition is the New Zealand national science challenge. An approach of developing healthier snack products with verifiable health-related claims through (re)formulation, could be translated into relevant dietary changes associated with potential improvement in public health.

\section{Acknowledgements}

The study was funded by the Early Career Research Fund from Unitec Institute of Technology, New Zealand.

\section{Author's Contributions}

MY designed and conducted the trial, analyzed and interpreted the data, wrote the draft of the manuscript, and handled the submission and review process. ER provided critical comments as the expert in the field. RJ participated data collection. SS contributed to the study design, critically reviewing and editing the manuscript. All authors read and approved the final manuscript.

\section{Conflicts of Interest}

The authors declare no conflicts of interest regarding the publication of this paper.

\section{References}

[1] Hess, J.M., Jonnalagadda, S.S. and Slavin, J.L. (2016) What Is a Snack, Why Do We Snack, and How Can We Choose Better Snacks? A Review of the Definitions of Snacking, Motivations to Snack, Contributions to Dietary Intake, and Recommendations for Improvement. Advances in Nutrition, 7, 466-475. https://doi.org/10.3945/an.115.009571

[2] Bellisle, F. (2014) Meals and Snacking, Diet Quality and Energy Balance. Physiology \& Behavior, 134, 38-43. https://doi.org/10.1016/j.physbeh.2014.03.010

[3] Sekiyama, M., Roosita, K. and Ohtsuka, R. (2012) Snack Foods Consumption Contributes to Poor Nutrition of Rural Children in West Java, Indonesia. Asia Pacific Journal of Clinical Nutrition, 21, 558-567.

[4] Svisco, E., Byker Shanks, C., Ahmed, S. and Bark, K. (2019) Variation of Adolescent Snack Food Choices and Preferences along a Continuum of Processing Levels: The Case of Apples. Foods, 8, 50. https://doi.org/10.3390/foods8020050

[5] Furchner-Evanson, A., Petrisko, Y., Howarth, L., Nemoseck, T. and Kern, M. (2010) Type of Snack Influences Satiety Responses in Adult Women. Appetite, 54, 564-569. https://doi.org/10.1016/j.appet.2010.02.015

[6] Yan, M.R., Parsons, A., Whalley, G.A., Kelleher, J. and Rush, E.C. (2017) Snack Bar Compositions and Their Acute Glycaemic and Satiety Effects. Asia Pacific Journal of Clinical Nutrition, 26, 624-629. 
[7] Hutchings, S.C., Low, J.Y.Q. and Keast, R.S.J. (2019) Sugar Reduction without Compromising Sensory Perception. An Impossible Dream? Critical Reviews in Food Science and Nutrition, 59, 2287-2307. https://doi.org/10.1080/10408398.2018.1450214

[8] Poti, J.M., Dunford, E.K. and Popkin, B.M. (2017) Sodium Reduction in US Households' Packaged Food and Beverage Purchases, 2000 to 2014. JAMA Internal Medicine, 177, 986-994. https://doi.org/10.1001/jamainternmed.2017.1407

[9] Zupanic, N., Hribar, M., Pivk Kupirovic, U., Kusar, A., Zmitek, K. and Pravst, I. (2018) Limiting Trans Fats in Foods: Use of Partially Hydrogenated Vegetable Oils in Prepacked Foods in Slovenia. Nutrients, 10, 355. https://doi.org/10.3390/nu10030355

[10] Euromonitor International (2016) New Lifestyles System Data 2016: Global Consumer Trends Survey Results. Euromonitor International.

[11] Mintel (2018) Global Food and Drink Trends 2018.

[12] Collaborators GBDD (2019) Health Effects of Dietary Risks in 195 Countries, 1990-2017: A Systematic Analysis for the Global Burden of Disease Study 2017. The Lancet, 393, 1958-1972.

[13] Slavin, J. (2004) Whole Grains and Human Health. Nutrition Research Reviews, 17, 99-110. https://doi.org/10.1079/NRR200374

[14] Aune, D., Norat, T., Romundstad, P. and Vatten, L.J. (2013) Whole Grain and Refined Grain Consumption and the Risk of Type 2 Diabetes: A Systematic Review and Dose-Response Meta-Analysis of Cohort Studies. European Journal of Epidemiology, 28, 845-858. https://doi.org/10.1007/s10654-013-9852-5

[15] Kendall, C.W.C., Esfahani, A. and Jenkins, D.J.A. (2010) The Link between Dietary Fiber and Human Health. Food Hydrocolloids, 24, 42-48. https://doi.org/10.1016/j.foodhyd.2009.08.002

[16] Lopez-Nicolas, R., Marzorati, M., Scarabottolo, L., Halford, J.C., Johnstone, A.M., Frontela-Saseta, C., Sanmartin, A.M., Ros-Berruezo, G. and Harrold, J.A. (2016) Satiety Innovations: Food Products to Assist Consumers with Weight Loss, Evidence on the Role of Satiety in Healthy Eating: Overview and in Vitro Approximation. Current Obesity Reports, 5, 97-105. https://doi.org/10.1007/s13679-016-0196-9

[17] Al-Ani, H.H., Devi, A., Eyles, H., Swinburn, B. and Vandevijvere, S. (2016) Nutrition and Health Claims on Healthy and Less-Healthy Packaged Food Products in New Zealand. British Journal of Nutrition, 116, 1087-1094. https://doi.org/10.1017/S0007114516002981

[18] Food Standards Australia New Zealand (2015) Nutrition, Health and Related Claims: Standard 1.2.7. In a Guide to the Development of a Food Standard for Australia and New Zealand. Food Standards Australia New Zealand.

[19] Rasane, P., Jha, A., Sabikhi, L., Kumar, A. and Unnikrishnan, V.S. (2015) Nutritional Advantages of Oats and Opportunities for Its Processing as Value Added Foods: A Review. Journal of Food Science and Technology, 52, 662-675. https://doi.org/10.1007/s13197-013-1072-1

[20] Tapola, N., Karvonen, H., Niskanen, L., Mikola, M. and Sarkkinen, E. (2005) Glycemic Responses of Oat Bran Products in Type 2 Diabetic Patients. Nutrition, $\mathrm{Me}$ tabolism \& Cardiovascular Diseases, 15, 255-261. https://doi.org/10.1016/j.numecd.2004.09.003

[21] Rebello, C.J., O’Neil, C.E. and Greenway, F.L. (2016) Dietary Fiber and Satiety: The Effects of Oats on Satiety. Nutrition Reviews, 74, 131-147. 
https://doi.org/10.1093/nutrit/nuv063

[22] Monro, J.A. (2013) Kiwifruit, Carbohydrate Availability, and the Glycemic Response. Advances in Food and Nutrition Research, 68, 257-271. https://doi.org/10.1016/B978-0-12-394294-4.00014-6

[23] International Organisation for Standardisation (2010) Determination of the Glycaemic Index and Recommendation for Food Classification. The International Organisation for Standardisation, Geneva.

[24] Rolls, B.J., Castellanos, V.H., Halford, J.C., Kilara, A., Panyam, D., Pelkman, C.L. Smith, G.P. and Thorwart, M.L. (1998) Volume of Food Consumed Affects Satiety in Men. American Journal of Clinical Nutrition, 67, 1170-1177. https://doi.org/10.1093/ajcn/67.6.1170

[25] Holt, S.H., Brand-Miller, J.C. and Stitt, P.A. (2001) The Effects of Equal-Energy Portions of Different Breads on Blood Glucose Levels, Feelings of Fullness and Subsequent Food Intake. Journal of the American Dietetic Association, 101, 767-773. https://doi.org/10.1016/S0002-8223(01)00192-4

[26] Macfie, H.J., Bratchell, N., Greenhoff, K. and Vallis, L.V. (1989) Designs to Balance the Effect of Order of Presentation and First-Order Carry-Over Effects in Hall Tests. Journal of Sensory Studies, 4, 129-148. https://doi.org/10.1111/j.1745-459X.1989.tb00463.x

[27] Lawless, H.T. and Heymann, H. (2010) Sensory Evaluation of Food: Principles and Practices. Springer, New York. https://doi.org/10.1007/978-1-4419-6488-5_3

[28] Li, B., Hayes, J.E. and Ziegler, G.R. (2014) Just-About-Right and Ideal Scaling Provide Similar Insights into the Influence of Sensory Attributes on Liking. Food Quality and Preference, 37, 71-78. https://doi.org/10.1016/j.foodqual.2014.04.019

[29] Federici, C., Detzel, P., Petracca, F., Dainelli, L. and Fattore, G. (2019) The Impact of Food Reformulation on Nutrient Intakes and Health, a Systematic Review of Modelling Studies. BMC Nutrition, 5, 2. https://doi.org/10.1186/s40795-019-0269-8

[30] Muth, M.K., Karns, S.A., Mancino, L. and Todd, J.E. (2019) How Much Can Product Reformulation Improve Diet Quality in Households with Children and Adolescents? Nutrients, 11, E618. https://doi.org/10.3390/nu11030618

[31] Blevins, S.M., Leyva, M.J., Brown, J., Wright, J., Scofield, R.H. and Aston, C.E. (2007) Effect of Cinnamon on Glucose and Lipid Levels in Non Insulin-Dependent Type 2 Diabetes. Diabetes Care, 30, 2236-2237. https://doi.org/10.2337/dc07-0098

[32] Akilen, R., Tsiami, A., Devendra, D. and Robinson, N. (2012) Cinnamon in Glycaemic Control: Systematic Review and Meta Analysis. Clinical Nutrition, 31, 609-615. https://doi.org/10.1016/j.clnu.2012.04.003

[33] Buttriss, J.L. (2013) Food Reformulation: The Challenges to the Food Industry. Proceedings of the Nutrition Society, 72, 61-69. https://doi.org/10.1017/S0029665112002868

[34] Lytton, T.D. (2010) Signs of Change or Clash of Symbols? FDA Regulation of Nutrient Profile Labeling. Health Matrix, 20, 93-144. 